\title{
Landdagsvalget.
}

I forste $0 \mathrm{~g}$ anden Valgkreds fandt Valget Sted under livlig Deltagelse fra Vælgernes Sile; i tredje og fjerde Valgkreds undlod Danskerne derimod at stemme i en Rrekke Distrikter, hvor Stillingen var særlig vanskelig paa Grund af den indviklede Valgmaade.

Det var paa Forhaand givet, at de hidtilværeude Landdagsmend for første og anden Valgkreds Hans Lassen og Gustav Johannsen vilde blive gjenvalgte, men de blev gjenvalgte med betydeligt flere Stemmer, end vi havde ventet. Cagtet Treklasse-Valgsystemet er en meget kunstig Valgmaade, frembød Landdagsvalget dog samme Billede som Rigsdagsvalget: Almindelig og delvis betydelig Fremgang. for Danskerne, Stilstand og delvis Tilbagegang for Tyskerne over det meste af Nordslesvig; derimod Stilstand delvis ogsaa Tilbagegang for Danskerne og nogen Fremgang for Tyskerne i Sognene nord for Flensborg Fịord og paa de vestlige Strøg mellem Flensborg, Tønder og Løgumlonktoster.

Stemmetallene fra alle Valyg siden 1884 peger i denne. Retning $0 \mathrm{~g}$ den Cdvikling, som de afspejler, stalfiestes ogsaa af andre Undersogelser, saaledes bl. a. af cund. mag. H. V. Clausens store Gaardmandsstatistik, som vil blive offentliggjort i næste Hafte af dette Tidsskrift.

Det maa nu betragtes som en Kjendsgjærning, at der er foregaaet et stærkt nationalt Opsving, og at Ianskerne som Folge deraf har giort betydelige Fremskriat i Nordslesvig i nyere Tid. Men paa den anden Side mata vor Tilbagegang i Mellemslesvig ogsaa betragtes som en Kjendsgjærning, der ikke kan nægtes. Man fortæller om en Kirke ved Vesterhavet, at den hver Juleaften flytter sig et Hanefjed længere ud imod Stranden. Saaledes har den nationale Grænse i Nordslesvig nu ogsaa i en Aarrække flyttet sig et Hanefjed imod Nord hver Juleaften. Bevagelsen er langsom, men saalænge Grænsen overhovedet synlig for- 
rykkes imod Nord, er der en national Fare tilstede, hvis Betydning det vil vare dumt at undervurdere.

Aarsagen til vort Tab ved Grænsen maa nærmest søges i clen Forskydning imod Nord af det danske Element, der er en uundgaaelig Folge af den fortsatte Udvandring sterlig fra Haderslev Vesterant. Vi haaber imidlertid, at denne Udvandring - som nu vasentlig kun omfatter Forældre, (ler vil gjenforenes med deres landtygtige Børn - snart vil ophore fuldstandigt, og at det voksende nationale Rore i Nordslesvig maa afføde en Bevagelse imod Syd ligesom den, der foresik i Halvtredserne, da ikke faa nordslesvigske Mand kjobte sig Ejendomme i Mellemslesvig.

De folgende Tabeller giver en Oversigt over de valgte Valgmænd i forste og anden Valghireds ved de to sidste Valg 1893 og 1888.

Haderslev Kreds.

\begin{tabular}{|c|c|c|c|c|}
\hline \multirow[b]{2}{*}{ Valgdistrikt: } & \multirow{2}{*}{\multicolumn{2}{|c|}{$\begin{array}{c}1893 \\
\text { Valgmænd }\end{array}$}} & \multicolumn{2}{|c|}{1888} \\
\hline & & & $\begin{array}{r}\text { Valg } \\
\text { danske }\end{array}$ & $\begin{array}{l}\text { end } \\
\text { tyske }\end{array}$ \\
\hline Haderslev By ............ & 2 & 31 & - & 30 \\
\hline Haistrup................ & 4 & - & 2 & 2 \\
\hline Kvistrup $\ldots \ldots \ldots \ldots \ldots \ldots$ & 2 & 1 & 2 & $\overline{1}$ \\
\hline 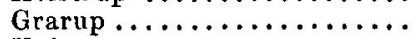 & $\overline{4}$ & - & 4 & - \\
\hline 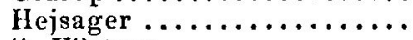 & $\mathbf{3}$ & - & 4 & 1 \\
\hline S. Vilstrup ............ & - & 4 & 一 & 3 \\
\hline Djernæs ............... & 3 & - & 2 & 1 \\
\hline 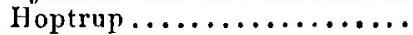 & 1 & 2 & 1 & 2 \\
\hline Gl. Haderslev . . . . . . . . & 1 & 2 & 1 & 2 \\
\hline Ulvslyst $\ldots \ldots \ldots \ldots \ldots \ldots$ & 3 & 1 & 3 & 2 \\
\hline Brek (Vonsbrk) ............ & 3 & 一 & 4 & - \\
\hline 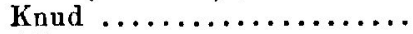 & 4 & 一 & 4 & - \\
\hline Aller $\ldots \ldots \ldots \ldots \ldots \ldots \ldots$ & $\mathbf{3}$ & 一 & 3 & 一 \\
\hline Hvinderup ............ & 3 & - & 3 & - \\
\hline Hjeruing............. & 3 & - & 1 & 2 \\
\hline Líristiansfelt . . . . . . . . & 1 & 3 & 4 & 一 \\
\hline Frørup $\ldots \ldots \ldots \ldots \ldots \ldots$ & 2 & 1 & 1 & $\mathbf{2}$ \\
\hline Steppinge ........... & 5 & 一 & 5 & 一 \\
\hline Sommersted .......... & 6 & 一 & 6 & - \\
\hline Vojens ............. & 3 & - & 2 & 2 \\
\hline Hammelev... & 3 & - & 3 & - \\
\hline Arnitlund .... & 3 & - & 1 & 2 \\
\hline N. Jersdal ......... & 5 & 一 & 5 & - \\
\hline Skrydstrup ............. & 3 & 1 & 3 & 2 \\
\hline 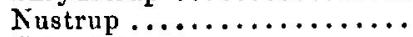 & 3 & - & 3 & - \\
\hline Dster-Linnet . . . . . . . . & 4 & - & 4 & $\longrightarrow$ \\
\hline Orsted $\ldots \ldots \ldots \ldots \ldots \ldots$ & 3 & 1 & 3 & 1 \\
\hline 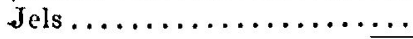 & 3 & I & 3 & $\ddot{2}$ \\
\hline Trausport... & 83 & 48 & 77 & 57 \\
\hline
\end{tabular}




\begin{tabular}{|c|c|c|c|c|}
\hline \multirow{3}{*}{ Valgdistrikt: } & \multicolumn{2}{|c|}{1893} & \multicolumn{2}{|c|}{1888} \\
\hline & \multicolumn{2}{|c|}{ Valgmand } & \multicolumn{2}{|c|}{ Valgmænd } \\
\hline & danske & tyske & danske & tyske \\
\hline Transport... & $8: 3$ & 48 & 77 & 57 \\
\hline Skodborg .............. & 4 & - & 5 & - \\
\hline 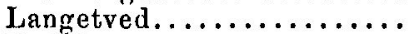 & 4 & 一 & 4 & - \\
\hline Rødding ............... & 2 & 1 & 2 & 1 \\
\hline 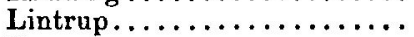 & 3 & $\bar{l}$ & 4 & - \\
\hline Hygum ............. & 5 & - & 5 & - \\
\hline Fol $\ldots \ldots \ldots \ldots \ldots \ldots$ & 3 & - & 2 & l \\
\hline Gram $\ldots \ldots \ldots \ldots \ldots \ldots$ & 3 & 一 & 3 & - \\
\hline Kastrup .............. & 3 & - & 3 & - \\
\hline Tirslund.............. & 3 & 一 & 3 & - \\
\hline Toftlund....... & 5 & 一 & 4 & 1 \\
\hline Branderup ............. & 3 & 一 & 3 & - \\
\hline Agerskov .............. & 6 & 一 & 6 & - \\
\hline Arrild $\ldots \ldots \ldots \ldots \ldots \ldots$ & $\mathbf{3}$ & - & 2 & $\mathbf{1}$ \\
\hline Arnum $\ldots \ldots \ldots \ldots \ldots \ldots$ & 4 & 一 & 4 & - \\
\hline Vodder.............. & 5 & - & 5 & - \\
\hline Rejsby ............ & 3 & - & 3 & - \\
\hline Brons . . . . . . . . . . . . & 3 & - & 3 & - \\
\hline Skærbæk .............. & 5 & - & 5 & - \\
\hline & 150 & 50 & 143 & 61 \\
\hline
\end{tabular}

\section{Aabenraa Kreds.}

\begin{tabular}{|c|c|c|c|c|}
\hline Valgdistrikt: & $\begin{array}{r}18 \\
\text { Valg } \\
\text { danske }\end{array}$ & 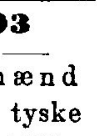 & $\frac{18}{\text { Valg }}$ & $\begin{array}{l}= \\
\text { tyske }\end{array}$ \\
\hline 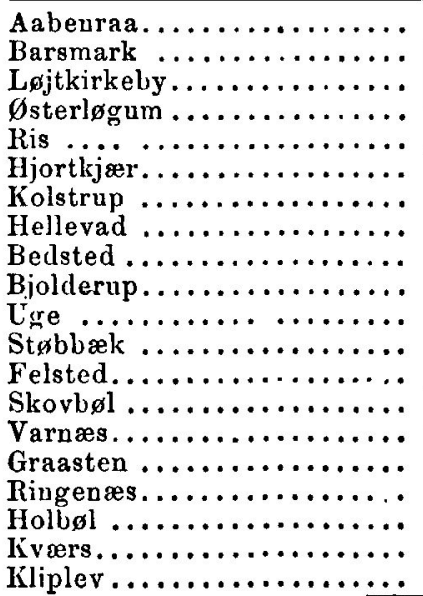 & $\begin{array}{l}2 \\
3 \\
3 \\
6 \\
2 \\
2 \\
4 \\
2 \\
5 \\
3 \\
4 \\
3 \\
5 \\
- \\
1 \\
4\end{array}$ & $\begin{array}{c}19 \\
1 \\
2 \\
1 \\
1 \\
4 \\
1 \\
3 \\
- \\
- \\
6 \\
5 \\
4 \\
2 \\
1\end{array}$ & $\begin{array}{l}2 \\
3 \\
3 \\
6 \\
3 \\
2 \\
3 \\
2 \\
5 \\
2 \\
3 \\
5 \\
3 \\
5 \\
2 \\
1 \\
2 \\
3 \\
\end{array}$ & $\begin{array}{r}21 \\
1 \\
2 \\
-1 \\
1 \\
1 \\
3 \\
1 \\
1 \\
1 \\
- \\
- \\
- \\
4 \\
4 \\
1 \\
2\end{array}$ \\
\hline & 49 & 50 & 55 & 47 \\
\hline
\end{tabular}


Sonderborg Kreds.

\begin{tabular}{|c|c|c|c|c|}
\hline \multirow[b]{2}{*}{ Valgdistrikt: } & \multicolumn{2}{|c|}{1893} & \multicolumn{2}{|c|}{1888} \\
\hline & $\begin{array}{r}\text { Valgn } \\
\text { dauske }\end{array}$ & $\begin{array}{l}\text { ænd } \\
\text { tyske }\end{array}$ & $\mid \begin{array}{r}\text { Valg } \\
\text { danske }\end{array}$ & $\begin{array}{l}\text { nd } \\
\text { tyolke }\end{array}$ \\
\hline 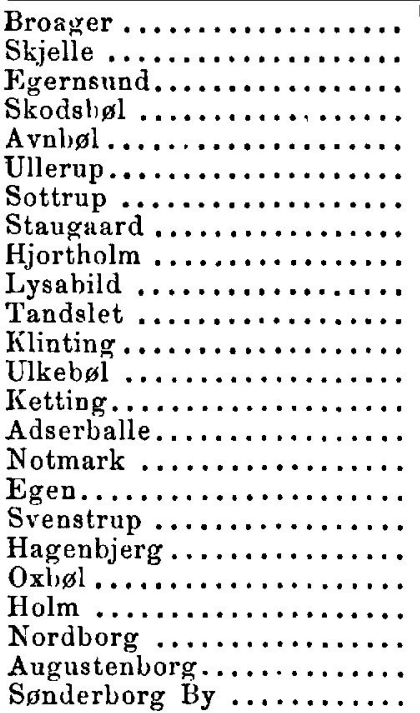 & $\begin{array}{l}2 \\
3 \\
4 \\
4 \\
5 \\
4 \\
3 \\
6 \\
2 \\
6 \\
4 \\
3 \\
2 \\
3 \\
3 \\
6 \\
4 \\
3 \\
4 \\
4 \\
1 \\
-1 \\
8\end{array}$ & $\begin{array}{l}4 \\
1 \\
4 \\
2 \\
= \\
= \\
\overline{-} \\
\overline{1} \\
\overline{1} \\
\frac{1}{Z} \\
= \\
\overline{1} \\
\overline{-} \\
\overline{3} \\
4 \\
12\end{array}$ & $\begin{array}{r}4 \\
4 \\
6 \\
2 \\
4 \\
3 \\
2 \\
6 \\
2 \\
6 \\
4 \\
3 \\
2 \\
3 \\
3 \\
6 \\
4 \\
3 \\
4 \\
5 \\
- \\
2\end{array}$ & $\begin{array}{l}\frac{2}{4} \\
\frac{1}{1} \\
1 \\
\frac{1}{1} \\
\frac{1}{1} \\
\frac{1}{-} \\
= \\
-1 \\
\frac{1}{4} \\
3 \\
18\end{array}$ \\
\hline & 84 & 34 & 78 & 39 \\
\hline
\end{tabular}

Hvis der ilke var forekonmet Uregelmæssigheder et Par Steder, vilde Forholdet have stillet sig endnu bedre for os. Men som Udfaldet blev maa det alligevel betegnes som en smuk Sejr.

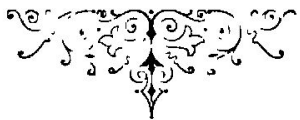

